\title{
Interações de bebês em creche
}

\author{
Adriana Mara dos Anjos \\ Katia De Souza Amorim \\ Cleido Roberto Franchi E Vasconcelos \\ Maria Clotilde Rossetti-Ferreira \\ Universidade de São Paulo - Ribeirão Preto
}

\begin{abstract}
Resumo
O artigo trata de eventos interativos de bebês com coetâneos. Inicialmente, abordamos concepções e métodos de estudo sobre interação de bebês na literatura, a partir da década de 1970. A seguir, apresentamos estudo empírico realizado através da análise de gravações em vídeo do projeto Processos de adaptação de bebês a creche, que acompanhou 21 bebês (4-14 meses) em creche universitária. A investigação deu-se em duas fases. A primeira, pela identificação de episódios interativos envolvendo os 21 bebês, considerando-se interação como fazer algo juntos. A segunda, pela análise microgenética dos episódios interativos de um bebê. Tal análise revelou freqüentes, fluidas e entrecortadas interações, que ultrapassam o fazer algo juntos, podendo o comportamento ser regulado mesmo à distância e mesmo que um dos parceiros não saiba que está regulando o comportamento do outro. Isso nos levou a tratar as interações como ocorrendo em um campo interativo, através da concepção de co-regulação do comportamento.
\end{abstract}

Palavras-chave: interação; bebês; análise microgenética; regulação do comportamento; campo interativo

\begin{abstract}
Infant's interactions at day care. The paper aims to discuss early peer interactive events. Initially, interactive conceptions and methodological issues from a literature review are introduced. Then, an empirical study is presented. It has been constructed from videotapes analysis of the Babies' adaptation into day care center research project, which has followed 21 babies (4-14 months of age), at a university day care center. Investigation included two phases. First, interactional episodes were identified based on an interaction conception of doing something together. The second phase resulted from a microgenetic analysis of all identified episodes related to one selected child. The study revealed frequent, brief, fluid and interrupted interactions. Yet, the analysis points toward interaction as going beyond doing something together, as behavior can be regulated from distance, while children are involved in diverse activities and, even if one of them is not aware that he/she is regulating the other partner's behavior. As such, interactions are considered as co-regulation within interactive fields.
\end{abstract}

Keywords: interaction; infant; microgenetic analysis; behavior regulation; interactive field

A o longo da história da Psicologia, muitos autores têm reiterado que a interação social é fundante ao desenvolvimento do ser humano (Rossetti-Ferreira, Amorim, \& Silva, 2004; Vygotsky, 1986; Wallon, 1959a, 1959b). Nesse sentido, um conjunto grande de pesquisas tem sido conduzido com a meta de investigar situações interativas, de modo a apreender e explicitar como elas acontecem, nas diferentes idades. E, ainda, de modo a destacar aspectos considerados centrais das mesmas ao desenvolvimento afetivo, social e cognitivo da pessoa.

Especificamente, as investigações sobre a capacidade interativa da criança têm se dado a partir de diferentes enfoques e concepções. Diversas correntes da Psicologia do Desenvolvimento, por exemplo, supõem a prioridade do ob- jeto sobre o parceiro social, como alvo de interesse da criança, em especial nos primeiros anos de vida. Conforme Pedrosa e Carvalho (1996), a consideração dessa prioridade reflete o pressuposto de que esses estudos podem estar embasados em proposições piagetianas e, portanto, de que certo grau de desenvolvimento cognitivo é condição para a interação social.

Outra gama de trabalhos tem investigado a capacidade interativa das crianças na sua relação com os adultos, em especial com a mãe. Alguns destes estudos embasam-se na Teoria do Apego (Bowlby, 1969; Ainsworth, Blehar, Waters, \& Wall, 1978), investigando a origem, a função e o desenvolvimento das relações sociais precoces do bebê com a mãe. Tais estudos partem de pressupostos que sustentam que a espécie humana é equipada com um número de sistemas 
comportamentais, dentre eles os relacionais, os quais contribuem para a sobrevivência da espécie.

Em uma outra vertente de estudos da relação do bebê com o adulto, Fogel (1993) concebe os bebês, desde o nascimento, como participantes ativos em um sistema cultural e que, ao comunicar-se, o bebê, assim como o adulto, emprega meios convencionais de movimentos e expressões dirigidos ao outro, como o sorriso e o olhar. Para o autor, uma préadaptação biológica prepara a criança para agir sobre o social e a modificá-lo, havendo uma reciprocidade de influências entre o indivíduo e o meio.

As capacidades interativas da criança com parceiros de mesma idade têm sido investigadas com menor frequiência, quando comparadas com relação aos demais parceiros. Essa freqüência se mostra menor ainda quando se consideram as capacidades interativas dos bebês com seus coetâneos. Porém, uma análise da revisão da literatura das últimas décadas indica que interações com os coetâneos vêm representando um crescente foco de interesse. Carvalho e Beraldo (1989) apontam a relevância desses estudos já que, em qualquer sociedade, ao longo dos primeiros anos de vida, o mundo social da criança passa a incluir contato com outras crianças. Ademais, esse contato tem ocorrido de forma cada vez mais precoce, em função de transformações sócio-econômicas e culturais, as quais têm promovido o compartilhamento da educação de crianças cada vez mais novas em ambientes coletivos do tipo creche (Amorim, Rossetti-Ferreira, \& Vitória, 2000).

Interessados em conhecer como pesquisadores da área têm investigado mais particularmente processos interativos de bebês com coetâneos, realizou-se uma revisão sobre esse tema.

\section{Estudos sobre interação de bebês na literatura científica}

Através da análise de revisão bibliográfica ${ }^{1}$, verificamos variados focos na investigação sobre a capacidade interativa do bebê. Além disso, identificamos que vários autores apontam para aspectos diversos que propiciam, promovem ou restringem as interações. E, ainda, que a área passou por intensas mudanças, tanto conceituais como metodológicas, ao longo das últimas três décadas.

$\mathrm{Na}$ década de 1970, de acordo com Lewis e Rosenblum (1975), estudos sobre interação questionavam a possibilidade de haver contribuições, a partir do contato com pares, para o desenvolvimento das competências das crianças, fossem estas competências cognitivas ou interpessoais. Para alguns autores, portanto, não era claro que o "contato" pudesse significar interação propriamente dita, e nem mesmo era clara a função da relação dos pares.

Outros autores, no entanto, vinham reconhecendo a existência de processos interativos de bebês, buscando definilos. Assim, segundo Eckerman, Whatley, e McGehee (1979), os bebês, antes de um ano de idade, são capazes de observar o outro, sorrir e vocalizar para o outro, oferecer e tomar brinquedos, imitar e fazer sons na busca de um contato social. Já para Hartup (1975) e Mueller e Lucas (1975), as amizades recíprocas consistiam de instâncias repetidas de dois bebês ou crianças próximas tocando o outro, manipulando o outro, dando ou pegando algo do outro, havendo uma seqüência de comportamentos socialmente orientados, contíguos e reciprocamente dirigidos.

Nesse período, usualmente, os estudos verificavam a presença do adulto e/ou do brinquedo como mediadores da interação (Ramey, Finkelstein, \& O’Brien, 1976), sendo esta referida como contato social (Vincze, 1970) ou comportamento socialmente dirigido (Becker, 1977).

Na década de 1980, Baudonnière (1988) afirma que, entre três meses e um ano de idade, manifesta-se o interesse do bebê por parceiros de idade, o qual pode ser observado através de comportamentos socialmente orientados, como sorrisos, ofertas, vocalizações e contatos físicos. Porém, para esse autor, seria discutível a capacidade de interação do bebê com o coetâneo, pelo fato desses comportamentos serem freqüentemente isolados e sem articulações que permitam interações mais longas e sustentáveis.

Já para Hay, Pederson, e Nash (1982), no primeiro ano de vida, as capacidades de trocas recíprocas antecedem a locomoção, a fala e as habilidades cognitivas maduras, sendo que os bebês podem interagir entre si, ainda que com habilidades e recursos limitados.

Aparecem novos trabalhos sobre o papel do brinquedo nas interações (Bakeman \& Adamson, 1984; Howes \& Stewart, 1987). Ainda, o termo interações de pares passa a ser aplicado aos bebês (Curry \& Jennings, 1982; Eckerman \& Didow, 1988; Hay, Pedersen \& Nash, 1982; Vandell, Wilson, \& Buchanan, 1980) e capacidades comunicativas passam também a ser estudadas com foco no afeto, nos gestos, na imitação e comunicação não-verbal (Deleau, 1988; Fogel \& Thelen, 1987; Rayna, 1987; Ross \& Lollis, 1987).

Ainda na década de 1980, vários pesquisadores começam a utilizar novos recursos de observação de crianças, especialmente a vídeo gravação (Camaioni, 1980; Oliveira, 1988; Rossetti-Ferreira, 1985, Stambak \& Verba, 1986). Esta, aliada à metodologia experimental que já vinha sendo utilizada na década anterior, resultou em novos avanços na área, já que o recurso possibilita a preservação do fenômeno, propiciando repetição da observação e mais tempo para reflexão sobre a mesma, possibilitando o enriquecimento de sua análise (Carvalho et al., 1996).

$\mathrm{Na}$ década de 1990, as preocupações dos autores caminharam no sentido de se aperfeiçoar métodos de investigação dos reguladores do comportamento e dos sistemas de interação, além das estratégias de aproximação social e das habilidades comunicativas (Carvalho \& Carvalho, 1990; Findji, Pecheux, \& Ruel, 1993; Montagner et al, 1990).

Além disso, o conceito de interação passou por re-elaborações. Para autoras como Carvalho, Império-Hamburger e Pedrosa (1997), por exemplo, o termo interação passou a ser concebido como englobando mais do que o fazer algo juntos, passando a contemplar a regulação recíproca, implícita e não necessariamente intencional. Trata, assim, da interação enquanto potencial de regulação entre os componentes de um sistema. Nesse sentido, os movimentos ou as transformações de comportamentos de um dos componen- 
tes (no caso, os bebês), não podem ser compreendidos sem que se considere a existência, os movimentos ou o comportamento de outros componentes (ou os outros bebês), mesmo que entre eles não haja uma troca explícita ou que não façam algo conjuntamente.

Ainda nesse período, houve o sentido de teorização dos processos interativos, como parte de outros processos do desenvolvimento do primeiro ano de vida, como os de intersubjetividade. Nesse sentido, em estudos longitudinal e transversal, Fiamenghi (1999), utilizando-se de um sistema de codificação de comportamentos de crianças, observou que crianças entre 6 a 9 meses são capazes de reconhecer no coetâneo um outro social. Ainda, referindo-se à consciência interpessoal ou consciência do self-e-do-outro, mostrou que bebês em díades, colocados face-a-face, já aos seis meses de idade manifestam comportamentos indicativos de reconhecimento intersubjetivo e habilidade sensível de comunicação, mediante a troca de sentimentos e gestos. Defende, assim, uma concepção de consciência interpessoal e das emoções que regulam todas as relações e trocas humanas, presentes já desde o primeiro ano de vida.

Através da revisão, portanto, identificamos uma relativa carência de estudos (quando comparados com outros processos interativos do bebê) que investiguem processos interativos de bebês com coetâneos. Além disso, percebemos mudanças importantes, nos últimos 30 anos, na forma de conceituar e apreender as interações que ocorrem entre bebês, durante o primeiro ano de vida, havendo mesmo importantes contradições entre as concepções. Ainda, foi possível identificar que a teorização dos processos interativos, dentro de uma perspectiva dialógica, a qual aparece em estudos da interação mãe-bebê, não é verificada nos estudos de bebês com seus pares.

Assim, partindo de um referencial sócio-histórico e considerando o ser e o desenvolver-se humano dentro de processos dialógicos, consideramos de relevância investigar tais processos sob essa ótica. Tal investigação caminha no sentido de se buscar contribuir tanto teoricamente com a questão, como com o historicamente recente e crescente campo da educação de bebês em ambientes coletivos, ajudando a subsidiar alguns aspectos com relação a sua prática.

Como um sub-projeto de um projeto integrado, o qual investigou diversos processos envolvendo 21 bebês que freqüentaram uma creche, a meta do presente trabalho foi investigar, a partir da perspectiva teórico-metodológica da rede de significações, se ocorriam processos interativos entre as crianças abaixo de 18 meses de idade. E, ainda, se positivamente identificados, analisar como se davam esses processos.

\section{Método}

\section{Os bebês e o contexto investigado}

O material empírico utilizado pelo estudo foi obtido no banco de dados do projeto integrado Processos de adaptação de bebês à creche. Este acompanhou o ingresso e a freqüência de 21 bebês (4-14 meses de idade ao ingresso) a uma creche universitária, no ano de 1994 (para detalhes do projeto, vide Rossetti-Ferreira, Amorim, \& Vitória, 1994). ${ }^{2}$

Esses 21 bebês frequientaram o módulo Rosa da creche. Nesse, os bebês encontravam-se reunidos em turmas, de acordo com idade e habilidades, a saber: T1 para os bebês de quatro a oito meses de idade; T2 para os de nove a doze; e, T3 para os de 12 a 14 meses, obedecendo a uma proporção de 6 bebês para cada educadora.

Duas educadoras eram responsáveis pelos bebês em cada turma, sendo que uma trabalhava no período da manhã e a outra à tarde. Havia uma hora de sobreposição dos seus horários de atividades, quando as educadoras passavam a responsabilidade e trocavam informações sobre as crianças. Apesar dessa divisão, todas as seis educadoras participavam da supervisão do conjunto de crianças do módulo.

O espaço destinado a essas crianças era composto por várias salas (sala de atividades, dormitório, solário, refeitório e banheiro), sendo que as crianças permaneciam, durante a maior parte do tempo, na sala de atividades. Esta era organizada em vários ambientes, onde havia colchões, estantes com brinquedos, caixas em que as crianças podiam entrar e brinquedos dispostos pelo chão. Usualmente, os bebês menores (subgrupo T1) permaneciam no colchão ou carrinho, enquanto que aqueles que já engatinhavam e/ou andavam deslocavam-se livremente pela sala, freqüentemente encontrando-se muito próximos uns aos outros.

Essa forma de organização do ambiente apóia-se primordialmente na proposta psicopedagógica dessa creche, que considera que as interações de crianças devam ser privilegiadas (Mello, 1999).

\section{Registros da situação de freqüência à creche}

Os registros realizados pelo projeto integrado foram vários, tendo sido feitas entrevistas de matrícula, fichas de observação (comportamento, estado e intercorrências de saúde), entrevistas (educadoras, técnicas e seis das mães dos 21 bebês) e gravações em vídeo.

Para o presente trabalho, utilizou-se, basicamente, as gravações em vídeo. Estas foram realizadas diariamente, ao longo dos três primeiros meses de frequiência à creche. Durante o primeiro mês, as gravações tiveram duração de três horas diárias, repartidas em três períodos: início da manhã (chegada à creche e separação dos familiares); horário do almoço; e, final da tarde (retorno dos pais). Nesse período, era freqüente a presença dos familiares, especialmente das mães, durante as filmagens. A partir do segundo mês, as gravações tiveram duração de duas horas diárias (horário do almoço e saída da creche). As gravações resultaram em um arquivo de 54 fitas de vídeo, equivalentes a 75 horas de gravação.

Vários foram os objetivos da gravação, dentre os quais se incluíam os eventos interativos dos bebês. As gravações foram feitas por câmera de vídeo móvel, possibilitando que acontecessem em um ambiente amplo e, ao mesmo tempo, permanecessem próximas aos sujeitos, registrando situações bastante sutis, detalhes das interações e expressões das crianças e dos adultos, na situação. 


\section{Coleta de dados e construção do corpus para análise}

A coleta e análise dos dados foram guiadas pela perspectiva teórico-metodológica da Rede de Significações (RedSig) (Rossetti-Ferreira, Amorim, \& Silva, 2000, 2004). Essa perspectiva propõe o ser humano como um ser complexo, dotado de capacidades interativas, desde o nascimento, já que considera que o bebê nasce com um repertório biológico complexo, com um alto grau de organização perceptiva e expressiva, com uma capacidade de reconhecer e responder ao outro, o que possibilita estabelecer e maximizar um intercâmbio com o outro social, potencializando sua interação com o mesmo (Meltzoff \& Moore, 1977; Papousek \& Papousek, 1989; Trevarthen, 1989).

Tais processos interativos ocorreriam através de uma "coordenação" ou "jogos de papéis", os quais levam as pessoas envolvidas a negociarem continuamente os significados que atribuem a si mesmas, ao outro e à situação como um todo (Oliveira, 1988). Entendendo essa relação, negociação e construção constante dos significados como inerentemente humanas, a perspectiva propõe que interações estabelecidas entre as pessoas (incluindo-se bebês) ocorrem através de uma contínua co-construção, que é sempre situada/contextualizada.

Nesses processos, as ações de ambos os participantes inter-relacionam-se dinâmica e corporificadamente. Ou seja, é através do próprio corpo que a criança dialogicamente experiencia o mundo e inicia suas relações consigo mesmo e com o outro, numa contínua relação com o outro (Amorim, 2004; Fogel, 1993).

Metodologicamente, de forma a se investigar os processos desenvolvimentais dialógicos humanos, a perspectiva da RedSig tem proposto que se mapeie os principais elementos participantes do processo, sendo didaticamente identificados os componentes pessoais, campos interativos e cenários, os quais se encontram dinâmica e dialeticamente interrelacionados, todos os quais estão imersos $\mathrm{em}$ e atravessados por uma matriz sócio-histórica. Esta teria uma natureza semiótica, sendo composta por elementos sociais, econômicos, políticos, históricos e culturais, os quais têm concretude no aqui-agora. A matriz, ainda, não é homogênea, visto ser sendo constituída por várias condições e discursos vinculados a diferentes períodos históricos e processos sociais, apresentando diferentes pesos e hierarquias de poder em determinada sociedade, cultura, subgrupo, contexto específico e relacionamento.

Através da articulação desses elementos, diversos campos interativos seriam propiciados e delimitados, favorecendo certas formas de relações, de organizações sociais, além de certos significados e sentidos através da organização do espaço, da rotina e dos discursos presentes em contextos específicos.

Considerar as interações e relações a partir de uma perspectiva dialógica implica, portanto, em pensá-las de foram relacional, social, histórica e cultural; implica em considerar o ser e o desenvolver-se dentro de uma perspectiva que toma a alteridade como básica.

\section{A coleta e análise de dados}

O processo de investigação de eventos interativos de bebês deu-se em duas fases. Uma primeira ocorreu através da observação repetida e cuidadosa das 54 fitas de vídeo, buscando-se identificar episódios interativos de bebês. Essa identificação foi guiada pela definição de episódio interativo, conforme proposto por Eckerman (1979), Baudonnière (1988) e Camaioni (1980), em que os parceiros em interação "fazem algo juntos" e obedecem a alguns critérios como proximidade física, gestos dirigidos ao outro, direcionamento do olhar e/ ou postural recíprocos. Uma vez identificados esses episódios, explicitávamos quais eram os participantes da interação, onde e quando esta ocorreu, além das atividades e características do processo interativo, registrando nossas impressões acerca do mesmo.

A segunda fase do trabalho deu-se com a seleção de um sujeito focal, através do sorteio de um dos 21 bebês investigados $(\text { Marcos) })^{3}$, o qual contava com 11 meses de idade ao ingresso na creche. Fez-se uma transcrição minuciosa de todos os episódios interativos desse bebê, através da qual buscouse apreender o contexto geral em que a criança estava inserida a cada momento. Procurou-se, ainda, descrever a concomitância com diferentes eventos, a seqüência com que cada evento ocorreu e interferiu no outro, além das ações, olhares e falas dos principais sujeitos envolvidos em cada situação. Nessa fase da investigação, definiu-se pela análise processual ou microgenética daqueles episódios (Vygotsky, 1986).

\section{Resultados e discussão}

\section{Primeira fase da análise de dados}

Inicialmente, o trabalho foi realizado através de uma primeira "imersão" no material empírico. Essa imersão só foi possível graças ao mergulho na situação, pela repetida tarefa de assistir às 54 fitas de vídeo, ora em velocidade normal, ora acelerada e ora em lenta.

Como já mencionado acima, partindo-se de critérios de interação enquanto fazer algo conjuntamente, identificávamos e registrávamos os episódios interativos dos 21 bebês. Os registros dessa primeira fase do trabalho resultaram na identificação de 366 episódios interativos, os quais, evidentemente, não eram igualmente divididos entre as 21 crianças. Na Figura 1, apresentamos o número de episódios interativos registrados para cada grupo de crianças, ao longo das semanas de freqüência.

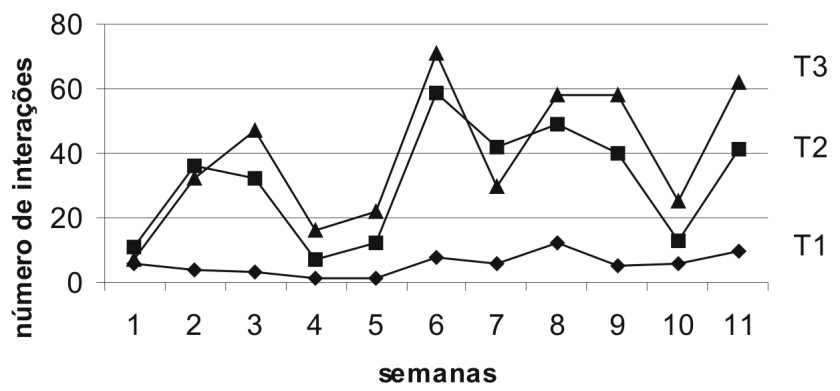

Figura 1. Número de interações, por turma, ao longo das semanas. 
Na primeira semana de ingresso na creche, o grupo de crianças que se destacou em número de episódios interativos foi o T2 (11 episódios). A partir da segunda semana, embora duas novas crianças tenham ingressado em cada grupo, o número de interações entre as crianças do grupo T1 diminuiu progressivamente, ocorrendo o inverso com os demais grupos.

Vale mencionar que, nessas primeiras semanas, especialmente, os bebês de quatro a sete meses permaneciam a maior parte do tempo ao lado da mãe ou em carrinhos, próximos às educadoras. Usualmente, nessas situações, os bebês ficavam mais afastados das outras crianças; ou, mesmo que fisicamente próximos, eram posicionados de frente para suas mães e, de certa maneira, tinham menor acesso às e/ou pelas outras crianças. Além disso, a partir do segundo mês de freqüência à creche, os bebês maiores passaram a freqüentar o solário, enquanto os mais novos permaneciam na sala de atividades, diminuindo ainda mais a possibilidade de interação entre as crianças de quatro a sete meses com as demais. Essas condições, de certa forma, podem ter contribuído para a escassez de eventos interativos observados nos bebês do subgrupo T1.

Por outro lado, isso não impedia que os bebês maiores, de nove a 14 meses, se interessassem pelos de mesma idade ou mesmo pelos menores, embora a presença dos pais, a interferência das educadoras e a multiplicidade de estímulos do ambiente acabassem por atuar de modo a reduzir e/ou interromper tais interações. Aqueles bebês, ainda, eram muito requisitados pelas crianças mais velhas, de outras turmas da creche, que iam brincar com eles, separando-os dos coetâneos.

Observa-se, ainda, uma flutuação na freqüência de episódios, ao longo do tempo, com uma diminuição de eventos interativos nas $4^{\underline{a}}, 5^{\mathrm{a}}$ e $10^{\mathrm{a}}$ semanas. Algumas hipóteses foram levantadas, mas como o objetivo desse estudo era verificar a ocorrência em si de eventos interativos, as hipóteses acabaram não sendo mais profundamente exploradas.

Além de se investigar a ocorrência e o número de episódios, estes acabaram por ser discriminados por categorias de interações - isto é, se ocorriam em duplas, trios ou agrupamentos com mais de três crianças.

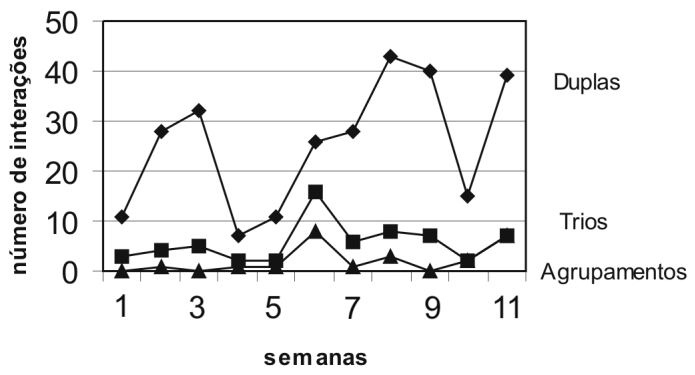

Figura 2. Número de interações, por categorias, ao longo das semanas.

A identificação de tão grande número de episódios acabou por surpreender os pesquisadores que, de início, carregavam as tradicionais concepções sobre a baixa capacidade interativa de bebês com coetâneos. Tal análise revelou que a freqüência dos mesmos aumentou com o passar do tempo e que, na primeira semana, eles ocorriam principalmente com a participação das crianças mais velhas, ou seja, os bebês de nove a 14 meses de idade. Nesse período, as situações interativas davam-se preferencialmente em duplas e, com o tempo, passaram a ocorrer também, apesar de que com uma freqüência muito menor, através dos agrupamentos com mais de três crianças. Estes agrupamentos tinham como característica se iniciarem em duplas, acabando por atrair outras crianças para a situação, a qual ia se re-configurando com o ingresso de cada novo participante.

Nessa fase, a análise dessas interações buscou identificar alguns aspectos das crianças, do ambiente e da situação em que elas se encontravam, de modo a contextualizar a ocorrência e a forma dos episódios. Confirmando estudos anteriores (Meneghini \& Campos-de-Carvalho, 2003), o modo como o ambiente físico é organizado favorece a ocorrência das interações. No caso da sala onde os bebês permaneciam, havia uma organização em espaços, estruturados de modo a favorecer que os bebês brincassem e se locomovessem livremente pelo chão, decorrendo daí freqüentes encontros com o desencadeamento de episódios interativos.

Além disso, quanto mais tempo e familiaridade com o ambiente, maior facilidade o bebê encontrava na exploração do mesmo. Também, com a entrada de novas crianças na creche, nas semanas seguintes, as crianças já há mais tempo no ambiente voltavam sua atenção aos mesmos, deixando um pouco de lado a novidade dos brinquedos e do ambiente físico, buscando, de modo geral, mais contato com esses novos parceiros.

Outros aspectos foram considerados como favorecedores dos eventos interativos. Conforme apontado por Franchi e Vasconcelos, Amorim, Anjos, e Rossetti-Ferreira (2003), apesar de aparentemente contraditório, a incompletude motora dos bebês foi reconhecida como facilitadora das interações. Assim, quando um bebê, por exemplo, vai atrás de uma bola que escapa de suas mãos e ele se depara com um outro bebê, a descoordenação e a dificuldade de realização de movimentos acaba por promover encontros mais próximos ou longos com o outro. Esta incompletude motora, portanto, pode representar um elemento capaz de propiciar o surgimento de novos episódios de interação e/ou mesmo de prolongar um episódio de interação entre crianças pequenas.

Apesar da busca de contextualização dos episódios interativos, entendeu-se que aquela contextualização se deu através de aspectos muito gerais. Por se tratar de um grupo grande de bebês, alguns dos tópicos apontados não necessariamente refletiam a situação específica de cada um deles. Circunstâncias mais pessoais, que poderiam estar contribuindo para favorecer ou restringir as interações de um certo bebê - como por exemplo, eventos de adoecimento, problemas familiares, mediação das educadoras e familiares -, não eram possíveis de serem analisadas e discutidas a partir dos dados, que tratavam mais da dinâmica do grupo como um todo. Sentia-se, portanto, a necessidade de especificar as condições em que os eventos interativos específicos ocorriam. 
Além disso, a análise dos episódios segundo a segundo apontou para o fato de que eles abarcavam mais do que o momento imediato em que dois ou mais bebês realizavam alguma atividade conjunta, como será explicitado mais adiante. Isso acabou por promover um questionamento das noções de interação que orientavam o olhar dos pesquisadores, fazendo-nos buscar novas conceituações através das quais se pudesse contemplar outros aspectos dos processos interativos.

Finalmente, se, nessa fase, a análise dos eventos respondia afirmativamente à primeira pergunta do trabalho - se bebês interagem -, pouco permitia explorar sobre como os processos transcorriam. Essa situação nos remeteu a uma segunda fase do trabalho, com a necessidade de acompanhar apenas um dos bebês e vários dos processos interativos estabelecidos por ele.

\section{Segunda fase de análise de dados - episódios interativos de Marcos}

Nesta segunda fase, conforme descrito na seção de Método, selecionou-se um sujeito focal (Marcos, de 11 meses) para um acompanhamento mais detalhado na creche, de modo a se rastrear as várias seqüências dos seus eventos interativos.

Dos vários episódios identificados, dois serão aqui apresentados.

Episódio 1: a cestinha. Ocorre no dia seguinte à entrada de Marcos na creche. Duração do episódio: 5 m 30 s. A Tabela 1 apresenta os participantes no episódio e suas respectivas idades.

Tabela 1

Participantes do episódio 1

\begin{tabular}{cc}
\hline Participantes & Idade (meses e dias) \\
\hline Marcos e Andréia & $11 \mathrm{~m} \mathrm{e} 22 \mathrm{~d}$ \\
Débora & $10 \mathrm{~m} \mathrm{e} 08 \mathrm{~d}$ \\
Susi & $09 \mathrm{~m} \mathrm{e} 15 \mathrm{~d}$ \\
\hline
\end{tabular}

Marcos e Andréia são irmãos gêmeos. Ambos já engatinham, sentam-se sozinhos e ficam em pé com apoio. Os dois encontram-se sentados no chão, lado-a-lado, bem próximos, conforme foram colocados pela mãe, minutos antes, diante de brinquedos, olhando-se enquanto vão executando suas atividades. Andréia pega uma cestinha que está no chão. Marcos olha a cestinha e começa a colocar brinquedos dentro dela. Andréia o observa. Ela puxa a cestinha, mas ele segura. A mãe dos gêmeos, que estava sentada próxima a eles, levanta-se e passa ao lado deles. Ambos olham para ela e acompanham seu movimento. A mãe passa direto por eles, sem parar. Imediatamente, eles voltam à atividade com a cesta. Agora, Marcos segura a cestinha e Andréia coloca um molho de chaves dentro dela. Ele balança a cabeça, como afirmativamente. Ela tenta puxar a cesta. Ele segura e vocaliza: “Aaahh...” Ela pega a chave de volta e Marcos olha em sua direção (irmã/chave). A mãe se aproxima para tirar a chupeta que está presa na roupa de Andréia. Esta olha para a mãe. Andréia balança o corpo e ergue os braços na direção da mãe, fazendo com que a chave caia de sua mão. Marcos pega a chave. A mãe não pega Andréia, que se volta para Marcos e aos objetos, pegando a cestinha do chão, após Marcos tê-la deixado, brincando com a chave. Andréia coloca um chocalho dentro dela. Marcos olha para a irmã. Ele pega a cesta de volta, puxando-a para perto de si. Andréia olha para trás, vira o corpo e faz menção de sair engatinhando. Marcos olha para a direção onde a irmã vai. Ele bate a cestinha no chão. Andréia volta-se e observa a ação do irmão, permanecendo no mesmo lugar. A mãe deles se aproxima e tira a chupeta de Marcos (a câmera move-se e tira as duas crianças de foco). Após 10 segundos, quando a câmera volta a focar essas crianças, Marcos está brincando com a cestinha e Andréia o observa. Nesse momento, Débora (10 meses e oito dias) aparece engatinhando e olha na direção de Marcos, da cestinha e de Andréia. Débora pára, sem ser notada por Marcos e Andréia que estão de costas para ela. Enquanto isso, Andréia toma a cestinha de Marcos. Ele observa a irmã e vai com o corpo na direção de Andréia/cestinha. Débora senta-se e olha para sua mãe que está sentada logo atrás dela. Ela faz cara de choro (manha). Sua mãe conversa com ela. Ela olha novamente para Marcos, para a cestinha e Andréia. Marcos pega a cestinha de volta. Andréia sai engatinhando, sorrindo. Marcos vira-se para trás e observa Débora resmungando e sua mãe falando com ela. Depois, Marcos e Débora olham para a frente, na mesma direção (pela posição da câmera, não dá para dizer para o que olham). Em seguida, Débora aproxima-se por trás e puxa a cestinha de Marcos. Ele segura. Ela continua tentando pegar, puxando-a. Marcos a segura e balança lateralmente a cabeça, como acenando "não". A mãe de Débora a chama e oferece uma bolinha. Ela olha para a mãe, larga a cestinha, mas não vai pegar a bola. Senta e olha para Marcos que volta a balançar a cesta. A câmera sai e, quando volta, trinta segundos depois, vemos que Marcos saiu e Débora está balançando a cesta para frente e para trás. Ela larga a cesta e sai, ao mesmo tempo em que Marcos aproxima-se novamente (pela sua postura, dá a impressão de que ela não o vê se aproximando). Ele pega a cestinha e volta a mexer com brinquedos dentro dela, balançaa. Solta a cesta e sai engatinhando. Débora que, pouco depois de largar a cesta, vê que Marcos estava novamente com a cestinha, volta engatinhando. Nesse mesmo instante, Marcos começa a se afastar desse local e da cesta. Susi ( 9 meses e 15 dias), que está próxima de Débora, observa-a mexendo com a cesta. Ambas olham para a mãe de Débora que passa por elas. Débora larga a cesta e sai engatinhando atrás da mãe, choramingando. Susi observa. Débora pára, olha na direção de Marcos, volta-se em direção de onde ficou a cestinha. Pega um chocalho que estava no meio do caminho. Senta-se. Balança o chocalho e olha em outra direção. Marcos está cerca de três metros de distância, brincando com um carrinho. Débora volta-se na direção da cestinha e a puxa. A câmera tira essas crianças de foco. 
Inicialmente, cabe mencionar que, apesar de duas das crianças serem irmãos gêmeos - e, portanto, terem uma maior familiaridade com o outro, apresentando mais freqüentes e intensos processos interativos -, tal episódio foi selecionado pela participação de duas outras crianças, nada conhecidas dos outros dois, e que vão ser centrais à discussão do episódio.

Com relação ao evento analisado, como dito, temos dois bebês bastante familiarizados entre si (irmãos gêmeos) em atividade conjunta, observando-se e regulando seu comportamento em relação ao outro, em alguns momentos de forma complementar (como quando Andréia coloca a chave na cesta que Marcos segura, e este balança a cabeça afirmativamente), enquanto que em outros não. No decorrer dessa interação, aparece um terceiro bebê (Débora) que observa a situação e vocaliza diante da dupla. Quando a primeira dupla se desfaz, o terceiro bebê entra na disputa pelo brinquedo com um dos gêmeos (Marcos). Essa nova dupla partilha atividades relativas ao mesmo objeto por algum tempo, separando-se posteriormente. Porém, o que se observa é que, apesar de se afastarem e estarem longe um do outro e do objeto, ainda que de forma interrompida, sua atenção volta-se ao outro e à cesta, com olhares, movimentos de corpo na direção do outro e de retorno e manipulação daquele objeto. Assim, apesar de distantes, na seqüência dos acontecimentos, esses bebês continuam a observar-se e a regular seus comportamentos em relação ao outro.

Interessante é que, quando o brinquedo alvo da disputa fica no chão, um e outro até o retomam em momentos distintos. Porém, de maneira muito breve, havendo perda de interesse com relação ao mesmo, acabando por ser abandonado ou relegado a segundo plano. Isso nos faz supor que o brinquedo ocupa um lugar de destaque quando em relação à outra criança participante. Parece-nos que há uma coordenação de comportamentos ou atividades, através da intermediação do outro. Há, assim, um sistema bebê-objeto-bebê, no qual a atração pelo objeto passa pelo outro.

Nesse caso analisado, há ainda um quarto bebê: Susi, que está próxima e os observa, mas que não se engaja em nenhuma atividade conjunta com eles. Apesar de não fazer algo junto a eles, parece ter seu comportamento em certo momento regulado pelos outros.

No conjunto desse episódio, ainda, observamos movimentos bruscos dos braços e da cabeça. Muita coisa acontece por conta da incompletude motora e, mesmo, pela atenção dirigida ao adulto que passa ou que chama a atenção no caso das mães e de outras pessoas presentes do ambiente. Observamos, também, que o corpo todo da criança participa dos episódios, expressando-se através de seu direcionamento, dos movimentos da cabeça dos bebês no contato com o outro, na direção do olhar, no balanço dos braços e nas vocalizações.

O episódio descrito não é curto. No entanto, apesar de ter uma duração de cinco minutos e meio, percebemos que os bebês dividem atenção com outras coisas que estão acontecendo no ambiente e outros brinquedos disponíveis, muitas vezes fazendo com que o episódio seja temporariamente in- terrompido, mas não determinando a perda total de interesse, sendo por vezes retomado.

De qualquer forma, pode-se afirmar que interações ocorreram, conforme critérios que destacam proximidade física, gestos dirigidos ao outro, direcionamento do olhar e/ou postural recíprocos. Além disso, verificamos também uma regulação dos comportamentos. Assim, apesar dos bebês não permanecerem o tempo todo fazendo coisas juntos, mesmo à distância, eles fazem algo ou têm comportamentos guiados pelo foco de atenção em relação à outra criança.

Esse aspecto da co-regulação do comportamento dos bebês, nos eventos interativos, é mais claramente explicitado na análise de outros episódios, como mostra o caso a seguir.

Episódio 2: a bola. Acontece no oitavo dia de frequiência de Marcos na creche. Duração do Episódio: $11 \mathrm{~m}$. A Tabela 2 apresenta os participantes no episódio e suas respectivas idades.

Tabela 2

Participantes do episódio 2

\begin{tabular}{cc}
\hline Participantes & Idade (meses e dias) \\
\hline Marcos e Andréia & $11 \mathrm{~m} \mathrm{e} 29 \mathrm{~d}$ \\
William & $13 \mathrm{~m} \mathrm{e} 14 \mathrm{~d}$ \\
Gustavo & $12 \mathrm{~m} \mathrm{e} 20 \mathrm{~d}$ \\
\hline
\end{tabular}

Willian tem 13 meses e já anda com bastante agilidade. Ele está de pé, próximo à sua mãe (que está sentada no colchão). Willian tem um tubo na mão e, por várias vezes, coloca e tira a mão de dentro do tubo. Em determinado momento, Marcos aparece engatinhando na direção de Willian. Quando Willian vê Marcos que vem engatinhando, vira-se de costas e sai batendo os pezinhos no chão, como a correr. Pouco depois, pára, volta-se para trás. Observa Marcos, sorrindo. Este, porém, parece alheio a Willian, olhando em outra direção. Willian, novamente, depois de olhá-lo, vira-se de costas e sai como que correndo. Pouco depois, pára, volta o corpo, olha para trás e vê Marcos aproximando-se. A mãe de Willian, percebe o olhar do filho e diz: "É o nenê, filho?" Ele olha para Marcos que o observa e, subitamente, dirige-se para o colo de sua mãe, abraçando-a, sorrindo, escondendo o objeto que carregava. Marcos, não atento aos dois, passa direto. Sua mãe diz: "É o nenê! Não fica com medo, não!" Willian sai do colo da mãe e caminha na direção de Marcos. No caminho, Willian pára, pega um outro brinquedo do chão. Nisso, Marcos volta-se para trás e observa à distância. Willian o vê olhando, sai correndo novamente para o colo da mãe, sorrindo, ao que a mãe diz: "Ai, que lindo!" Marcos senta e o observa. Depois, sai engatinhando na direção de Willian que estava saindo do colo da mãe, ao qual retorna rapidamente, abraçando-a. Marcos engatinha lentamente e se dirige para uma caixa de madeira que está ao lado de Willian. Essa caixa é grande (é possível várias crianças entra- 
rem dentro dela ao mesmo tempo) e tem um espelho ao fundo. Neste momento, as duas crianças se encontram há cerca de um metro e meio de distância um do outro. Willian, ainda no colo da mãe, observa Marcos. Em seguida, vai na direção de Marcos, com uma bola na mão. Marcos senta e o observa. Nesse momento, Willian volta-se para a mãe, correndo e sorrindo. A mãe diz: "É nenê." Marcos engatinha, senta, pega brinquedos no chão. Willian, há mais ou menos um metro de distância, no colo da mãe, observa Marcos e vai até ele. Marcos olha para ele. Willian passa, vai na direção da caixa onde Marcos estava, mas não entra. Volta para a mãe, coloca a mão em seu rosto. Volta na direção de Marcos que o observa. Willian passa direto e vai para a caixa e movimenta o corpo dentro dela, como a dançar (há uma música de fundo tocando no ambiente). Marcos olha para o outro lado, deixa o brinquedo e sai engatinhando. Instantes depois, Willian sai da caixa, e olha para Marcos que está do outro lado da sala. Ele coloca a bola na boca e olha para a direção em que Marcos está. A educadora o chama e diz: "Vem cá, vem." Ele vai nesta direção e aponta para a cortina de tubinhos, próximo a ele. Ela diz: "É, cortina." Marcos dança sentado, perto da educadora. Ele não olha para Willian. Marcos engatinha entrando para o fundo de um espaço delimitado por pequenas estantes de brinquedos e com algumas almofadas. Willian o observa. A educadora fica conversando com Willian, dizendo para ele dançar. Ele dança, em pé. Joga fora a bola que tem nas mãos. Depois, Willian entra no cantinho e pega outra bola, saindo logo em seguida, rapidamente. Gustavo entra no cantinho e olha para Willian. Este olha para Gustavo e sai. Sua mãe o chama dizendo que há uma outra bolinha perto. Willian olha para a mãe e fica dançando, com a bolinha na boca, sem se dirigir à bolinha que foi apontada. Volta com a bola na boca. No colo da educadora está Andréia, irmã gêmea de Marcos. Marcos aproxima-se de Willian, pelo lado de dentro da estante e observa Willian, que ainda está com a bola na boca. Entre eles há uma cerca de $50 \mathrm{~cm}$ de altura. Marcos aproxima-se da cerca, balançando o corpo freneticamente, dançando, observando Willian. Marcos segura na cerca. Willian vira-se e vocaliza na direção da mãe, balançando os braços e a bolinha. Cada um de um lado da cerca. A educadora coloca Andréia em pé, apoiada na grade. Marcos a observa. Marcos levanta-se, apoiado nas grades da cerca. Willian vira-se de costas e sai, rapidamente, com a bola na mão. Pouco depois, Willian volta-se na direção de Marcos, balançando a bola Leva-a na direção de Marcos. Marcos leva sua mão à bolinha que está na mão de Willian. Willian vira-se em direção à sua mãe, mas volta-se para Marcos em seguida. Volta a levar a bolinha, agora na boca de Marcos, que fica com a bolinha na boca. Willian sai vocalizando: "Aaahh...". Sua mãe diz: "A outra bolinha ali." Ele observa, olha na direção da bolinha e, em seguida, olha para Marcos no cantinho. Marcos sai de lá engatinhando e vocalizando, sem a bolinha. Willian o observa e vai atrás dele, ainda observando. A câmera sai de foco.

Neste episódio, temos uma longa série de comportamentos que precedem a ação conjunta. $\mathrm{O}$ fazer algo juntos, para Marcos e William, é algo que acontece em um tempo muito curto, o que reforça a verificação do que foi apontado no episódio anterior. Porém, o comportamento de um bebê
(Willian) está sendo regulado pelo do outro (Marcos), por um tempo muito mais longo do que o tempo em que fazem algo juntos, mesmo sem Marcos se dar conta disso.

No início do episódio, a brincadeira para Willian é sair correndo de Marcos, na direção do colo da mãe, como que "fugindo" dele. Porém, pelas suas expressões, não parece que Willian sente-se ameaçado por Marcos, como sua mãe em uma de suas falas parece sugerir. Ao contrário, parece haver uma motivação, um interesse pelo outro, atribuindo um significado lúdico à situação. Marcos, no entanto, não se mostra atento ao outro, não manifestando interesse por ele, passando ao seu lado e dirigindo-se a outro ponto da sala.

Com o aparente desinteresse da parte de Marcos, poderse-ia dizer que o episódio não se efetivou. No entanto, essa seria uma interpretação baseada em expectativas construídas a partir de padrões de interação verificados nos adultos (adultocentrismo) ou em processos interativos de crianças mais velhas. Tal interpretação desconsidera a atração que uma criança exerce sobre a outra. Além disso, nesse caso, as intercalações entre o fazer independente da presença ou interesse pelo outro e os comportamentos socialmente dirigidos foram se alternando até eles chegarem a um momento em que trocam a bola. Esse momento provavelmente só foi possível devido ao potencial de regulação que vinha se estabelecendo há quase dez minutos. Ainda, entende-se que Willian faz o mesmo movimento de colocar a bola na boca de Marcos, movimento que antes fazia consigo mesmo. Ou seja, há uma seqüência de atividades, com uma complexidade crescente da situação.

Importante notarmos que a metodologia de análise microgenética, de acompanhar a história do processo, foi o que nos permitiu verificar que a outra criança estava sendo regulada pelo outro, havendo uma busca contínua por interação. Entretanto, as ações iniciadas por um dos bebês em direção ao outro não necessariamente resultaram em atividade conjunta. Ainda, as ações foram se delineando de forma entrecortada, interrompida por diferentes situações, sendo, posteriormente, retomadas. O campo interativo daqueles bebês estendia-se, assim, para além das atividades de ação conjunta, incluindo comportamentos socialmente dirigidos, ainda que não correspondidos pelo outro.

Tal visão nos aproximou do conceito de campo interativo, como proposto por Carvalho, Império-Hamburger, e Pedrosa (1997), no qual a interação é compreendida como um potencial de regulação entre os componentes do campo, sendo um campo de interação definido pela natureza de seus componentes que interagem, ao mesmo tempo que os constitui.

\section{Considerações finais}

Ao iniciar este trabalho, compartilhávamos da definição de interação enquanto fazer algo juntos. Partindo desta perspectiva, conseguimos, numa primeira fase de análise de dados, responder afirmativamente à questão: se crianças de até 18 meses de idade interagem. No entanto, sobre o modo como esse processo especificamente se dá, nessa faixa etária, pouco sabíamos. 
Nesse sentido, optamos por uma nova fase, na qual recorremos à análise microgenética. Essa análise nos levou a verificar que várias ações e emoções das crianças evidenciavam uma busca pelo outro, sendo que nem todas as buscas culminavam em interações propriamente ditas. Evidentemente, muitos desses eventos acabavam por se perder, enquanto que outros se desdobravam e se concretizavam. Assim, identificou-se que, mesmo no primeiro ano de vida, os comportamentos de um se mostravam com frequiência regulados pelo outro, pela ação do outro, esta estando ou não dirigida ao primeiro.

Dentro do estudo específico, no contexto de ambiente coletivo em que foi realizado, com o espaço organizado de forma a promover eventos interativos, em que há uma cultura de interação de bebês privilegiada já na proposta psicopedagógica da creche, foi possível, nas duas fases de análise, verificar a ocorrência de um grande número de episódios interativos em que o fazer algo juntos é observado. Os episódios foram identificados como fluidos e entrecortados, mas não como breves. A fluidez dos episódios pode ser explicada, em parte pela organização do espaço físico, cheio de atrativos para os bebês, e também pela própria presença dos adultos, pais e educadores, que por ali transitam. Essas características do ambiente, tanto do ponto de vista físico como a presença de adultos, contribuem para que a atenção da criança muitas vezes se desvie do parceiro de interação.

A análise possibilitou apreender que não é o fazer algo juntos - o que na maioria das vezes é o comportamento mais facilmente observável e, este sim, breve -, que pode explicar a interação. Aquela análise permitiu ir além desses momentos, permitindo-nos dizer que os eventos interativos abarcam muito mais do que esse fazer algo juntos, sendo o comportamento regulado, mesmo à distância, ou ainda, mesmo que um dos parceiros não saiba que está regulando o comportamento do outro. Os processos passaram, assim, a ser entendidos dentro de um "campo interativo", onde há interesses pelo outro, orientação de comportamentos dirigidos a e derivados pelo outro, além de regulação de suas ações pela ação do outro.

\section{Agradecimentos}

Os autores agradecem a Ana M. A. Carvalho pela leitura e sugestões; e à $F A P E S P$, à $C A P E S$ e ao $C N P q$ pelos financiamentos recebidos.

\section{Referências}

Ainsworth, M., Blehar, M. C., Waters, E., \& Wall, S. (1978). Patterns of attachment: a psychological study of the strange situation. Hillsdale, New Jersey: Erlbaum.

Amorim, K. S. (2004, fevereiro). Dialogia e a RedSig. Manuscrito não-publicado (Palestra apresentada no IX Encontro Científico do CINDEDI), Universidade de São Paulo, Ribeirão Preto.

Amorim, K. S., Rossetti-Ferreira, M. C., \& Vitória, T. (2000). A rede de significações como perspectiva para a análise do processo de bebês na creche. Cadernos de Pesquisa, 109(3), 115-143.

Bakeman, R., \& Adamson, L. B. (1984). Coordinating attention to people and objects in mother-infant and peer-infant interaction. Child Development, 55 , 1278-1289.
Baudonnière, P. M. (1988). L'évolution des compétences à communiquer: chez l'enfant de 2 à 4 ans. Paris: Presses Universitaires de France.

Becker, J. M. (1977). A learning analysis of the development of peer-oriented behavior in nine-month-old infants. Developmental Psychology, 13, 481-491.

Bowlby, J. (1969). Attachment and Loss. Vol. 1: Attachment. Nova York: Basic Books.

Camaioni, L. (1980). L'interazione tra bambini. Roma: Armando Armando.

Carvalho, A. M. A., \& Beraldo, K. E. A. (1989). Interação criança-criança: ressurgimento de uma área de pesquisa e suas perspectivas. Cadernos de Pesquisa, 71, 55-61.

Carvalho, A. M. A., Bergamasco, N. H. P., Lyra, M. C. D. P., Pedrosa, M. I. P. C., Rubiano, M. R. B., Rossetti-Ferreira, M. C., Oliveira, Z. M. R., \& Vasconcellos, V. M. R. (1996). Registro em vídeo na pesquisa em psicologia: reflexões a partir de relatos de experiência. Psicologia: Teoria e Pesquisa, 12(3), 261-267.

Carvalho, A. M. A., \& Carvalho, J. E. C. (1990). Estratégias de aproximação social em crianças de dois a seis anos. Psicologia USP, 1(2), 117-126.

Carvalho, A. M. A., Império-Hamburger, A., \& Pedrosa, M. I. (1997). Interaction, regulation and correlation: a conceptual discussion and empirical examples in the context of human development. In M. Lyra \& J. Valsiner (Orgs.), The construction of psychological processes in the course of interpersonal communication (pp. 135-151). Norswod: Ablex.

Curry, N. E., \& Jennings, K. D. (1982, Abril). Toddlers' social play. Comunicação apresentada em Annual Meeting of the Association for the Anthropological Study of Play, London, Ontario, Canada.

Deleau, M. (1988). Interaction, imitation et communication non-verbale du nourrison. Psychologie Française, 33(1-2), 37-44.

Eckerman, C. O. (1979). The human infant in social interactions. In R. R. Cairns (Org.), The analysis of social interactions: methods, issues and illustrations (pp. 163-178). New Jersey: Lawrence Erlbaum.

Eckerman, C. O., \& Didow, S. M. (1988). Lessons drawn from observing young peers together. Acta Paediatrica Scandinavica-Suppl., 344, 55-70.

Eckerman, C. O., Whatley, J. L., \& McGehhe, L. J. (1979). Approaching and contacting the object another manipulates: a social skill of the 1-year-old. Developmental Psychology, 15, 585-593.

Fiamenghi, G. A. (1999). Conversas dos bebês. São Paulo: Hucitec.

Findji, F., Pecheux, M. G., \& Ruel, J. (1993). Dyadic activities and attention in the infant: a developmental study. European Journal of Psychology of Education, 8(1), 23-33.

Fogel, A. (1993). Developing through relationships. Chicago: University Chicago Press.

Fogel, A., \& Thelen, E. (1987). Development of early expressive and communicative action: Reinterpreting the evidence from a dynamic systems perspective. Developmental Psychology, 23(6), 747-761.

Franchi e Vasconcelos, C. R., Amorim, K. S., Anjos, A. M. A., \& RossettiFerreira, M. C. (2003). A incompletude como virtude: interação de bebês na creche. Psicologia: Reflexão e Crítica, 16(2), 293-301.

Hartup, W. W. (1975). The origins of friendships. In M. Lewis \& L. A. Rosenblum (Orgs.), Friendship and peer relations (pp. 11-26). Nova York: Wiley.

Hay, D. F., Pedersen, J., \& Nash, A. (1982). Dyadic interaction in the first year of life. In K.H. Rubin \& H. Ross. (Orgs.), Peer relationships and social skills in childhood (pp. 11-39). Nova York: Springer-Verlag.

Howes, C., \& Stewart, P. (1987). Child's play with adults, toys and peers: an examination of family and child-care influences. Developmental Psychology, 23(3), 423-430.

Lewis, M., \& Rosenblum, L. A. (1975). Friendship and peer relations. Nova York: Wiley.

Mello, A. M. A. (1999). História da carochinha: uma experiência para a educação de crianças abaixo de 3 anos em creche. Dissertação de mestrado não-publicada. Universidade de São Paulo, Ribeirão Preto, SP.

Meltzoff, A. N., \& Moore, M. K. (1977). Imitation of facial and manual gestures by human neonates. Science, 198, 75-78. 
Meneghini, R., \& Campos-de-Carvalho, M. I. (2003). Arranjo espacial na creche: espaço para interagir, brincar isoladamente, dirigir-se socialmente e observar o outro. Psicologia: Reflexão e crítica, 16(2), 367-378.

Montagner, H., Magnusson, M., Casagrande, C., Restoin, A., Bel, J. P., Hoang, P. N., Ruiz, V., Delcourt, S., Gauffier, G., \& Epoulet, B. (1990). Une nouvelle methode pour l'étude des organizateurs de comportements et des systemes d'interaction du jeune enfant. Les premières données. PsychiatrieEnfant, 33(2), 391-456.

Mueller, E., \& Lucas, T. (1975). A developmental analysis of peer interaction among toddlers. In M. Lewis \& L. A. Rosenblum (Orgs.), Friendship and peer relations (pp. 223-257). Nova York: Wiley.

Oliveira, Z. M. R. (1988). Jogo de papéis: uma perspectiva para análise do desenvolvimento humano. Dissertação de doutorado não-publicada, Universidade de São Paulo, São Paulo.

Papousek, H., \& Papousek, M. (1989). Ontogeny of social interactions in newborn infants. In C. Von Euler, H. Forssberg, \& H. Langercrantz (Orgs.), Neurobiology of early infant behavior (pp. 217-225). Nova York: Stockton.

Pedrosa, M. I., \& Carvalho, A. M. A. (1996). A interação social e a construção da brincadeira. Cadernos de Pesquisa, 93, 60-65.

Ramey, C. T., Finkelstein, N. W., \& O’brien, C. (1976). Toys and infant behavior in the first year of life. Journal of Genetic Psychology, 129, 341-342.

Rayna, S. (1987). Étude de la communication preverbale entre jeunes enfants. Pediatrie, 42(9), 711-714.

Ross, H. S., \& Lollis, S. P. (1987). Communication within infant social games. Developmental Psychology, 23(2), 241-248.

Rossetti-Ferreira, M. C. (1985, outubro). Comunicação entre crianças. In Sociedade de Psicologia de Ribeirão Preto (Org.), Anais da XV Reunião Anual de Psicologia (Vol. 1, 100-109). Ribeirão Preto: Autor.
Rossetti-Ferreira, M. C., Amorim, K. S., \& Silva, A. P. S. (2000). Uma perspectiva teórico-metodológica para análise do desenvolvimento humano e do processo de investigação. Psicologia: Reflexão e Crítica, 13(2), 281-293.

Rossetti-Ferreira, M. C., Amorim, K. S., \& Silva, A. P. S. (2004). Rede de significações: alguns conceitos básicos. In M. C. Rossetti-Ferreira, K. S. Amorim, A. P. S. Silva, \& A. M. A. Carvalho (Orgs.), Rede de significações e o estudo do desenvolvimento humano (pp. 23-34). Porto Alegre: Artmed.

Rossetti-Ferreira, M. C., Amorim, K. S., \& Vitória, T. (1994). A creche enquanto contexto possível de desenvolvimento da criança pequena. Revista Brasileira de Crescimento e Desenvolvimento Humano, IV(2), 35-40.

Stambak, M., \& Verba, M. (1986). Organization of some social play among toddlers: an ecological approach. In E. Mueller \& C. R. Cooper (Orgs.), Process and outcome in peer relationships (pp. 229-247). Nova York: Academic.

Trevarthen, C. (1989). Development of early social interactions and the affective regulation of brain growth. In C. Von Euler, H. Forssberg, \& H. Langercrantz (Orgs), Neurobiology of infant behaviour (pp. 191-216). Nova York: Stockton.

Vandell, D. L., Wilson, K. S., \& Buchanan, N. R. (1980). Peer interaction in the first year of life: an examination of its structure, content and sensitivity to toys. Child Development, 51, 481-488.

Vincze, M. (1970). The social contacts of infants and young children reared together. Early Child Development and Care, 1, 99-109.

Vygotsky, L. S. (1986). A formação social da mente. São Paulo: Martins Fontes.

Wallon, H. (1959a). O papel do outro na consciência do eu. In M. J. G. Werebe \& J. Nadel-Brulfert (Orgs.), Henri Wallon (2 ${ }^{\underline{a}}$ ed., pp. 158-167). São Paulo: Ática.

Wallon, H. (1959b). Os meios, os grupos e a psicogênese da criança. In M. J. G. Werebe \& J. Nadel-Brulfert (Orgs.), Henri Wallon (2ª ed., pp. 168-178). São Paulo: Ática.

\section{Notas}

1 A revisão abrangeu os anos de 1978 a 2002, através de 58 buscas, pelo cruzamento de diferentes palavras, em cinco bases de dados (Medline, PsycInfo, Lilacs, Eric e Scielo). O levantamento resultou em mais de 4.800 resumos de artigos publicados em periódicos nacionais e internacionais, além de livros e/ou capítulos de livros. Desses, apenas 45 artigos tratavam especificamente de interações de crianças de zero a 18 meses de idade com seus coetâneos.

2 As famílias dos bebês e as educadoras concordaram em participar do estudo, após terem sido esclarecidos a respeito dos objetivos do mesmo.

3 Nome fictício.

Adriana Mara dos Anjos é mestranda em Psicologia do Desenvolvimento na Faculdade de Filosofia, Ciências e Letras de Ribeirão Preto da Universidade de São Paulo.

Katia de Souza Amorim é pós-doutoranda em Psicologia do Desenvolvimento na Faculdade de Filosofia, Ciências e Letras de Ribeirão Preto da Universidade de São Paulo.

Cleido Roberto Franchi e Vasconcelos é pós-doutor em Psicologia do Desenvolvimento na Faculdade de Filosofia, Ciências e Letras de Ribeirão Preto da Universidade de São Paulo.

Maria Clotilde Rossetti-Ferreira, livre-docente pela Faculdade de Filosofia Ciências e Letras de Ribeirão Preto-USP, é professora titular na mesma instituição. Endereço para correspondência: Departamento de Psicologia e Educação da FFCLRP-USP; Av. Bandeirantes 3900 (Campus da USP); Ribeirão Preto, SP; CEP 14040-901.E-mail: mcrferre@usp.br 